\title{
Avaliação dos indicadores de desempenho operacionais e de qualidade do Sistema Nacional de Informações sobre Saneamento para sistemas de abastecimento de água e esgotamento sanitário
}

\section{Evaluation of the operational and quality performance indicators of the Brazilian National System of Information in Sanitation for water supply and sanitation systems}

Bernardo Costa Mundim ${ }^{1 *}$ | Isaac Volschan Junior ${ }^{1}$

ORCID ID

Mundim BC (D) https://orcid.org/0000-0003-0879-3650
DOI: https://doi.org/10.36659/dae.2020.079

Volschan Junior I (D) https://orcid.org/0000-0001-8634-8857

\section{Resumo}

$\mathrm{O}$ artigo avalia os indicadores de desempenho operacionais e de qualidade do Sistema Nacional de Informações sobre Saneamento (SNIS) para sistemas de abastecimento de água (SAA) e esgotamento sanitário (SES). Levantaram-se os indicadores operacionais e de qualidade praticados por 11 sistemas nacionais e internacionais de avaliação, selecionaram-se 24 indicadores da base SNIS de 2015, visando à identificação de suas recorrências e aplicabilidades pelos demais. Por meio do Método Delphi, realizou-se uma consulta a 38 especialistas do setor de saneamento para a definição do grau de importância de cada indicador selecionado na avaliação de desempenho de SAA e SES. Os resultados demonstraram que $58 \%$ dos indicadores do SNIS são utilizados pelos demais sistemas avaliados e nenhum indicador obteve média inferior a classificação importante. Conclui-se que alguns indicadores do SNIS devem ser revistos e que os todos os indicadores selecionados foram considerados importantes para avaliar SAA e SES.

Palavras-chave: Abastecimento de água. Esgotamento sanitário. Indicadores de desempenho. SNIS.

\section{Abstract}

The paper evaluates the operational and quality performance indicators of the Brazilian National System of Information in Sanitation (SNIS) for water supply (SAA) and sanitation systems (SES). The operational and quality indicators practiced by 11 national and international evaluation systems were raised, 24 indicators were selected from the 2015 SNIS's base, aiming to identify their recurrences and applicability by the others. Through the Delphi Method, a consultation was conducted with 38 specialists from the sanitation sector to define the degree of importance of each selected indicator in the performance evaluation of SAA and SES. The results showed that $58 \%$ of the SNIS's indicators are used by the other evaluated systems and no indicator obtained mean inferior to the important classification. It's concluded that some indicators of SNIS should be reviewed and that all the selected indicators were considered important for evaluating SAA and SES.

Keywords: Water supply. Sanitation. Performance indicators. SNIS.

\footnotetext{
${ }^{1}$ Universidade Federal do Rio de Janeiro - Rio de Janeiro - Rio de Janeiro - Brasil.

*Autor correspondente: bernardo.mundimagmail.com.
} 


\section{INTRODUÇÃO}

A Lei $n^{\circ}$ 11.445/2007, que estabelece as diretrizes nacionais para o saneamento básico em nosso país, prevê o instrumento de avaliação de desempenho da prestação dos serviços, por meio do: (i) estabelecimento de padrões de indicadores de qualidade da prestação de serviços; (ii) metas progressivas de expansão e de qualidade dos serviços e os respectivos prazos; (iii) monitoramento dos custos; (iv) avaliação da eficiência e eficácia dos serviços prestados; e, (v) padrões de atendimento ao público e mecanismos de participação e informação (BRASIL, 2007).

Alegre et al. (2006) definem indicador de desempenho (ID) como uma medida quantitativa de um aspecto particular do desempenho de uma entidade gestora ou do seu nível de serviço. Esses autores consideram o ID como um instrumento que auxilia o monitoramento da eficiência e eficácia da entidade gestora, e que, por ser uma medida quantitativa simples, facilita uma avaliação que de outro modo seria mais complexa e subjetiva.

Para Silva e Basílio Sobrinho (2006), indicador de desempenho é uma medida quantitativa de um aspecto particular de uma empresa, que expressa o nível atingido em relação a um determinado objetivo. Assim, é possível avaliar diretamente a eficiência e a eficácia da gestão de uma companhia.

Por sua vez, Molinari (2006) define que os indicadores de desempenho são uma tradução sintética dos aspectos mais relevantes da gestão de uma empresa, de mais a mais, simplificam a análise e a compreensão de conceitos mais complexos.

Nesse contexto, a utilização de indicadores de desempenho surge como uma ferramenta extremamente importante na avaliação de desempenho de sistemas de abastecimento de água e esgotamento sanitário.

Os indicadores de desempenho são geralmente calculados pela razão entre variáveis da mesma natureza ou de natureza distinta. Eles podem ser adimensionais, expressos em porcentagem, ou intensivos, como por exemplo a quantidade de extravasamentos de esgotos sanitários por extensão de rede coletora de esgotos (ALEGRE et al., 2006).

Indicadores de desempenho a serem utilizados na avaliação da prestação de serviços de água e esgotos devem cumprir requisitos fundamentais, dentre os quais se destacam (MATOS et al., 2003; ALEGRE et al., 2006; MOLINARI, 2006; ABNT, 2012):

- Definição explícita, com uma interpretação concisa e inequívoca;

- Formulação a partir de variáveis que possam ser facilmente e confiavelmente medidas e por um custo razoável;

- Relação com uma área geográfica delimitada (e, no caso de análise comparativa, convém que esteja relacionado à mesma área geográfica);

- Relação com um período de tempo bem definido (por exemplo, anual, trimestral);

- Comparação explícita de acordo com os objetivos almejados e de forma a simplificar uma análise que de outra forma seria complexa;

- Aplicável aos serviços de saneamento com diferentes características e diversos graus de desenvolvimento;

- Representação dos aspectos mais relevantes do desempenho do prestador de serviços, visando à racionalização da quantidade de indicadores e evitando repetições desnecessárias.

O Sistema Nacional de Informações sobre Saneamento é um importante sistema de informações do setor de saneamento brasileiro, concebido pelo Governo Federal em 1996. Com o advento da Lei $n^{\circ} 11.445 / 2007$, criou-se o Sistema Nacional de Informações em Saneamento Básico (SINISA), permitindo a institucionalização do 
atual SNIS e, mais do que isso, dando a ele maior envergadura em termos de abrangência e escopo (SNIS, 2017).

O SNIS tem como objetivo constituir-se em uma ferramenta para auxiliar no(a): i) planejamento e execução de políticas públicas de saneamento; ii) orientação da aplicação de recursos; iii) conhecimento e avaliação do setor de saneamento; iv) avaliação de desempenho dos prestadores de serviços; v) aperfeiçoamento da gestão; vi) orientação de atividades regulatórias e de fiscalização; e vii) exercício do controle social (SNIS, 2018).

Apoia-se em um banco de dados administrado na esfera federal, que contém informações e indicadores de caráter operacional, gerencial, financeiro e de qualidade sobre a prestação de serviços de abastecimento de água, esgotamento sanitário, manejo de resíduos sólidos urbanos e manejo de águas pluviais urbanas dos municípios brasileiros (SNIS, 2017, 2018).

Os indicadores e as informações sobre os serviços sobreditos são atualizados anualmente. Entretanto, para os serviços de água e esgotos, o início corresponde ao ano base de 1995, enquanto para o manejo de resíduos sólidos urbanos o ano de referência é o de 2002; já para o manejo de águas pluviais urbanas, é o ano de 2015 (SNIS, 2017, 2018).

É importante salientar que os prestadores de serviços são convocados a fornecer as informações para o SNIS e, em caso de não fornecimento, o prestador de serviços se torna inadimplente com a instituição, o que impede o acesso aos recursos federais para investimentos (SNIS, 2017).

O SNIS publica anualmente um glossário de termos e uma relação de indicadores, onde constam nomes, definições, unidades de medida das informações primárias e indicadores e fórmulas de cálculo desses últimos. Essa é uma grande contribuição para o completo entendimento dos dados e para o estabelecimento de uma linguagem única no setor, permitindo a integração de diferentes bancos de dados e comparações de desempenho entre os prestadores de serviços (MIRANDA, 2006).

Nesse cenário, pelo fato de o SNIS consolidar dados atualizados anualmente e por ter se tornado o maior e mais importante banco de dados do setor de saneamento brasileiro, justifica-se a elaboração deste artigo, uma vez que contribui para o seu desenvolvimento ao avaliar a relevância, a aplicabilidade e o objetivo de seus indicadores de desempenho operacionais e de qualidade para sistemas de abastecimento de água e esgotamento sanitário, com base na comparação com outros 10 sistemas nacionais e internacionais de avaliação e por meio de uma consulta a especialistas do setor de saneamento.

\section{METODOLOGIA}

SNIS (2017) divide os indicadores de desempenho para abastecimento de água e esgotamento sanitário em 5 dimensões, sendo: econômicofinanceiros e administrativos; operacionais água; operacionais - esgotos; balanço; e qualidade. Do universo de 84 indicadores, 43 são do domínio operacional e de qualidade, sendo esses os objetos deste estudo, especificamente para o ano base de 2015 .

Preliminarmente, visando à caracterização de sua recorrência e aplicabilidade, e, portanto, de sua relevância, foram identificados indicadores da base SNIS que apresentassem formulação e objetivos similares, sendo selecionados para fim do presente trabalho aqueles contemplados por pelo menos um dos demais sistemas nacionais e internacionais de avaliação, a saber: Associação Brasileira de Agências de Regulação (ABAR), Prêmio Nacional da Qualidade em Saneamento 
(PNQS), Agência Reguladora de Serviços Públicos Delegados do Estado do Ceará (ARCE), Asociación de Entes Reguladores de Agua Potable y Saneamiento de las Américas (ADERASA), American Water Works Association (AWWA), Office of Water Services (OFWAT), Entidade Reguladora dos Serviços de Águas e Resíduos (ERSAR), Water Services Association of Australia (WSAA), International Water Association (IWA) e The International Benchmarking Network for Water and Sanitation Utilities (IBNET) (MATOS et al., 2003; ALEGRE et al., 2006; XIMENES, 2006; ADERASA, 2007; ARCE, 2013; AWWA, 2013; OFWAT, 2013; ERSAR, 2015; ABES, 2016; BOM, 2016; IBNET, 2016; SNIS, 2017).

Selecionados os indicadores do SNIS e com base em suas respectivas formulações e objetivos, por similaridade, foi quantificada a recorrência dos mesmos nos demais sistemas nacionais e inter- nacionais de avaliação. É a partir desses resultados que o trabalho então promove uma análise crítica sobre a aplicabilidade e o efetivo objetivo de alguns dos indicadores do SNIS.

Posteriormente, com intuito de avaliar o grau de importância de cada indicador selecionado na avaliação de desempenho de prestadores de serviços de abastecimento de água e esgotamento sanitário, realizou-se uma consulta a diversos especialistas do setor de saneamento: agências reguladoras, empresas projetistas, meio acadêmico e prestadores de serviços.

A consulta foi executada segundo o Método Delphi (ESTES; KUESPERT, 1976; GORDON, 1994; WRIGHT; GIOVINAZZO, 2000), sendo realizada em duas rodadas. A sequência de execução é apresentada na Fig. 1.

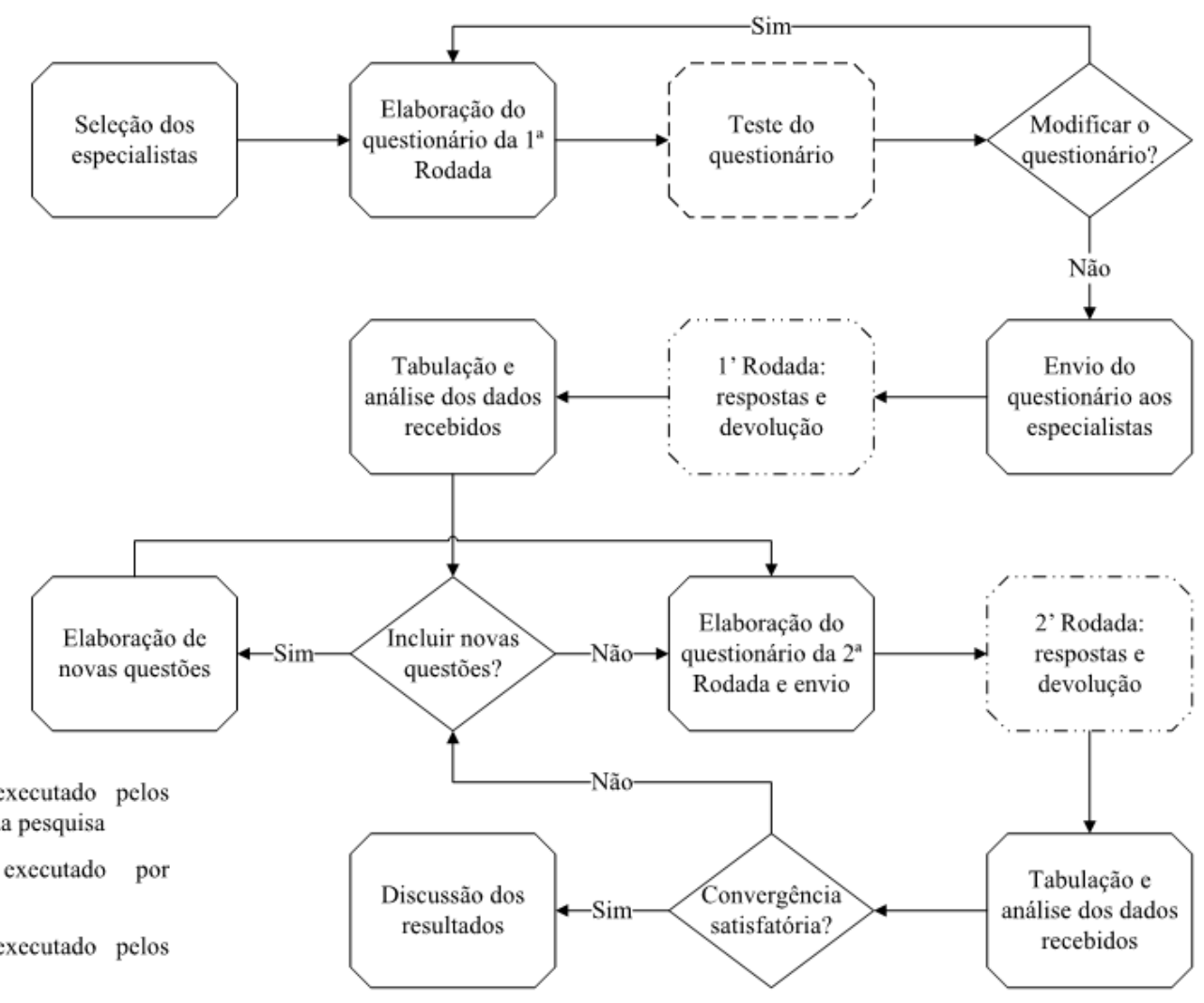

Legenda:

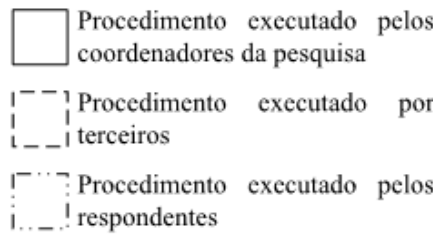

Figura 1 - Sequência de execução da consulta segundo o Método Delphi. Fonte: Adaptado de Wright e Giovinazzo (2000). 
$\mathrm{Na} 1^{\mathrm{a}}$ rodada da consulta, elaborou-se um questionário, que abordou, resumidamente, a temática e o objetivo geral do presente trabalho; ademais, continha as instruções para o preenchimento das questões.

O questionário, em formato Excel, foi enviado via correio eletrônico aos respondentes, que deveriam responder à seguinte pergunta: "Na sua opinião, qual a importância dos indicadores listados a seguir para a avaliação do desempenho operacional e de qualidade de prestadores de serviços de abastecimento de água e esgotamento sanitário?".

Na sequência, os respondentes precisariam classificar os indicadores selecionados segundo seus graus de importância na avaliação de desempenho em questão, conforme a seguinte graduação: 1 - irrelevante; 2 - pouco importante; 3 - importante; 4 - muito importante; e, 5 - de fundamental importância.

Por exemplo, na hipótese de um especialista julgar que um indicador é de fundamental importância na avaliação de desempenho operacional e de qualidade de prestadores de serviços de água e esgotos, ele daria o valor 5 , caso contrário, se o indicador fosse irrelevante, ele atribuiria o valor 1 .

Destaca-se que os especialistas tiveram a opção de se abster de julgamento em caso de dúvida em relação à resposta e de escrever comentários.

De acordo com Wright e Giovinazzo (2000), o Método Delphi busca a convergência das respostas, o que representa uma consolidação do julgamento de um grupo de especialistas.

Nessa lógica, elaborou-se um questionário para a $2^{\mathrm{a}}$ rodada da consulta, que continha as mesmas informações do questionário utilizado na $1^{\mathrm{a}}$ rodada acrescido de dois novos dados: as respostas do especialista para a $1^{\text {a }}$ consulta e os valores mais frequentes fornecidos por todos respondentes na $1^{\mathrm{a}}$ rodada para os indicadores de desempenho, ou seja, corresponde em estatística descritiva ao termo moda.

O questionário da $2^{\mathrm{a}}$ rodada foi enviado aos especialistas que participaram da $1^{\mathrm{a}}$ rodada, que deveriam reavaliar suas respostas da $1^{\mathrm{a}}$ consulta diante da moda de cada indicador de desempenho. Além disso, os mesmos tiveram a opção de escrever comentários e, caso fosse deixado em branco alguma classificação de indicador, foi considerado o valor da $1^{\text {a }}$ rodada da consulta.

Consoante com a $1^{\mathrm{a}}$ rodada, o questionário da $2^{\mathrm{a}}$ rodada, em formato Excel, foi enviado aos especialistas por correio eletrônico.

Por conseguinte, de posse dos resultados da $2^{\mathrm{a}}$ rodada da consulta, calculou-se a média aritmética dos graus de importância de cada indicador de desempenho, o que resultou em um único valor para cada indicador.

Por fim, pôde-se realizar uma análise crítica quanto aos resultados da pesquisa realizada com os especialistas do setor de saneamento.

\section{RESULTADOS E DISCUSSÃO}

Considerando todos os 11 sistemas de avaliação objetos do estudo, incluindo o SNIS, foram analisados 612 indicadores de desempenho operacionais e de qualidade, sendo 332 referentes aos serviços de abastecimento de água, 233 aos serviços de esgotamento sanitário e 47 a ambos os serviços. A Fig. 2 detalha a quantidade de indicadores identificados em cada um dos sistemas de avaliação. 


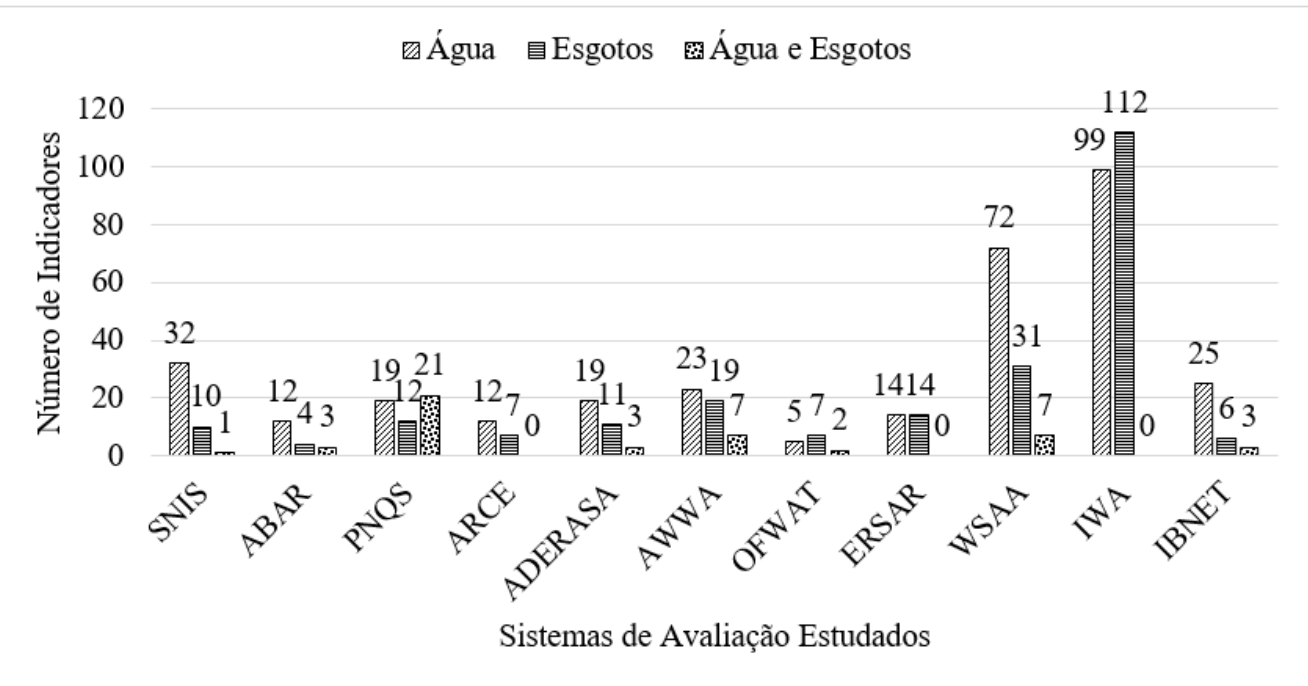

Figura 2 - Quantidade de indicadores de desempenho operacionais e de qualidade por sistema de avaliação estudado.

Observa-se na Fig. 2 que o esgotamento sanitário é considerado menos importante que o abastecimento de água por diversos sistemas de avaliação o que, consequentemente, não contribui para a evolução e melhor prestação dos serviços de esgotos. Tal fato parece ser representado pelo menor número de indicadores que estão disponíveis para avaliar o desempenho operacional e de qualidade de sistemas de esgotamento sanitário. Nesse contexto, excetuam-se as entidades AWWA, OFWAT, ERSAR e IWA, que apresentam quantidades similares de indicadores para ambos os sistemas de abastecimento de água e esgotamento sanitário; entretanto, insere-se o SNIS, de forma contundente, ao apresentar, relativamente, muito menor quantidade de indicadores de esgotamento sanitário do que de abastecimento de água.

Como ilustra o gráfico da Fig. 3, dentre os 30 indicadores operacionais e os 13 indicadores de qualidade que compõem a base do SNIS, foram identificados, por similaridade quanto à formulação e aos objetivos, respectivamente, 17 e 8 indicadores nos demais sistemas de avaliação.

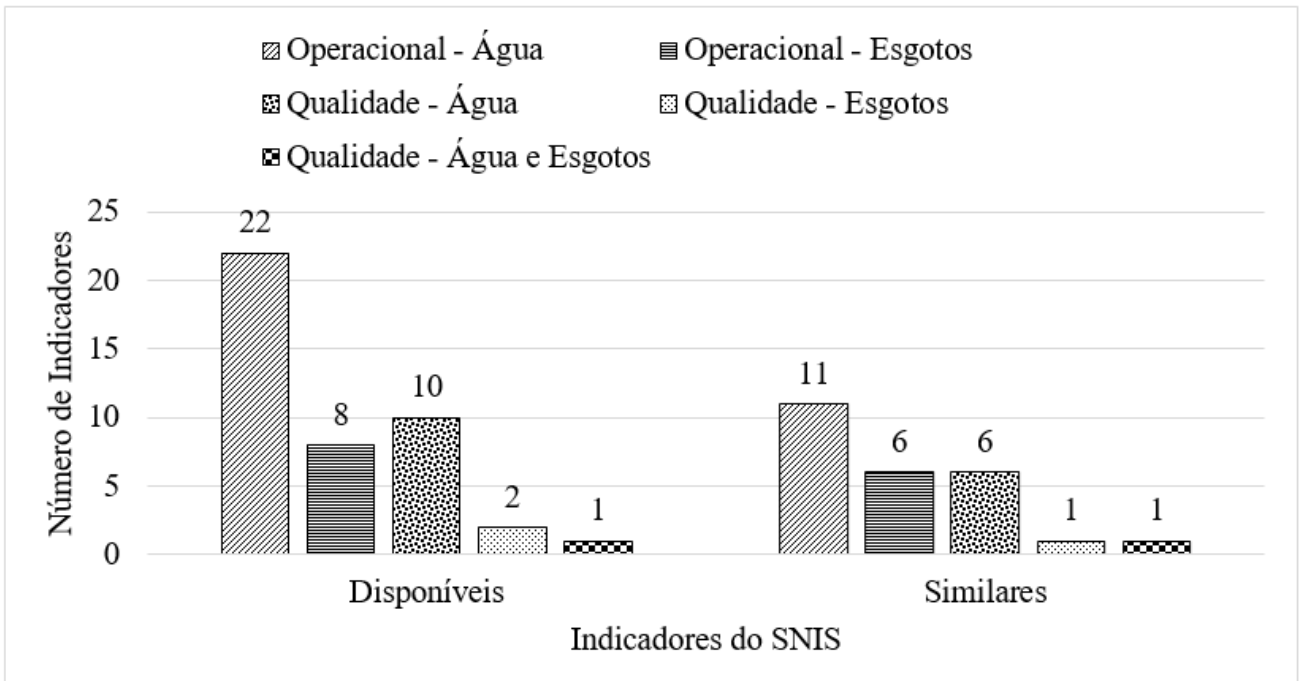

Figura 3 - Indicadores operacionais e de qualidade do SNIS similares aos dos demais sistemas de avaliação. 
Da observação da Fig. 3, constata-se que, dos 43 indicadores de desempenho de caráter operacional e de qualidade do SNIS, somente 25 são também considerados pelos demais sistemas de avaliação, o que permite o entendimento de que $42 \%$ da quantidade total de indicadores não são relevantes para os demais sistemas de avaliação.

Por meio da figura supracitada, verifica-se ainda que apesar da maior quantidade de indicadores operacionais para os serviços de abastecimento de água, somente a metade mostrou-se recorrente nos demais sistemas de avaliação, o que também permite o entendimento de que os mesmos não sejam relevantes para os demais sistemas de avaliação.

Por outro lado, apesar da menor quantidade de indicadores operacionais relativos aos serviços de esgotamento sanitário, observa-se que somente 2 desses não são efetivamente utilizados pelos sistemas avaliados, o que demonstra a relevância dos demais indicadores.

Por fim, observa-se que o SNIS contém mais indicadores no campo operacional do que no âmbito de qualidade, o que pode representar a priorização pela avaliação da operacionalidade dos sistemas de abastecimento de água e esgotamento sanitário.

A quantidade de sistemas de avaliação que também apresentam indicadores de desempenho operacionais e de qualidade similares aos que constam na base SNIS é detalhada na Tabela 1, expressa na forma de grau de recorrência por tipo de indicador.

Tabela 1 - Quantidade de sistemas de avaliação que apresentam indicadores similares aos que constam na base

\begin{tabular}{|c|c|c|c|}
\hline Serviço & Dimensão & Código SNIS - Indicador (Unidade) & $\begin{array}{l}\text { Grau de } \\
\text { Recorrência }\end{array}$ \\
\hline Água & Operacional & IN023 - Índice de atendimento urbano com rede de água (\%) & 3 \\
\hline Água & Operacional & IN055 - Índice de atendimento total com rede de água (\%) & 5 \\
\hline Água & Operacional & IN022 - Consumo médio per capita de água $\left(\mathrm{L} \cdot \mathrm{hab}^{-1} \cdot \mathrm{dia}^{-1}\right)$ & 2 \\
\hline Água & Operacional & IN053 - Consumo médio de água por economia $\left(\mathrm{m}^{3} \cdot\right.$ econ $\left.^{-1} \cdot \mathrm{mês}^{-1}\right)$ & 1 \\
\hline Água & Operacional & IN009 - Índice de hidrometração (\%) & 5 \\
\hline Água & Operacional & IN011 - Índice de macromedição (\%) & 1 \\
\hline Água & Operacional & IN049 - Índice de perdas na distribuição (\%) & 2 \\
\hline Água & Operacional & IN050 - Índice bruto de perdas lineares $\left(\mathrm{m}^{3} \cdot \mathrm{km}^{-1} \cdot \mathrm{dia}^{-1}\right)$ & 3 \\
\hline Água & Operacional & IN051 - Índice de perdas por ligação (L.lig ${ }^{-1} \cdot$ dia $\left.^{-1}\right)$ & 5 \\
\hline Água & Operacional & IN013 - Índice de perdas faturamento (\%) & 6 \\
\hline Água & Operacional & IN058 - Índice de consumo de energia elétrica em sistemas de abastecimento de água (kWh.m-3) & 1 \\
\hline Esgotos & Operacional & $\begin{array}{c}\text { IN024 - Índice de atendimento urbano com coleta de esgotos sanitários referido aos municípios } \\
\text { atendidos com água (\%) }\end{array}$ & 1 \\
\hline Esgotos & Operacional & $\begin{array}{l}\text { IN047 - Índice de atendimento urbano com coleta de esgotos sanitários referido aos municípios } \\
\text { atendidos com esgoto (\%) }\end{array}$ & 2 \\
\hline Esgotos & Operacional & $\begin{array}{c}\text { IN056 - Índice de atendimento total com coleta de esgotos sanitários referido aos municípios } \\
\text { atendidos com água (\%) }\end{array}$ & 5 \\
\hline Esgotos & Operacional & IN016 - Índice de tratamento dos esgotos em relação aos esgotos coletados (\%) & 3 \\
\hline Esgotos & Operacional & IN046 - Índice de tratamento dos esgotos em relação aos esgotos gerados (\%) & 2 \\
\hline Esgotos & Operacional & IN059 - Índice de consumo de energia elétrica em sistemas de esgotamento sanitário (kWh.m³) & 1 \\
\hline Água & Qualidade & IN075 - Incidência das análises de cloro residual fora do padrão (\%) & 4 \\
\hline Água & Qualidade & IN079 - Índice de conformidade da quantidade de amostras - cloro residual (\%) & 2 \\
\hline Água & Qualidade & IN076 - Incidência das análises de turbidez fora do padrão (\%) & 3 \\
\hline Água & Qualidade & IN080 - Índice de conformidade da quantidade de amostras - turbidez (\%) & 1 \\
\hline Água & Qualidade & IN084 - Incidência das análises de coliformes totais fora do padrão (\%) & 3 \\
\hline Água & Qualidade & IN085 - Índice de conformidade da quantidade de amostras - coliformes totais (\%) & 1 \\
\hline Esgotos & Qualidade & IN082 - Extravasamentos de esgotos por extensão de rede (extrav.km-1) & 5 \\
\hline Água e Esgotos & Qualidade & IN083 - Duração média dos serviços executados (horas.serviço-1) & 1 \\
\hline
\end{tabular}

Fonte: Adaptado de SNIS (2017). 
Quando se avalia a Tabela 1, atenta-se para o fato de haver 2 indicadores bastante semelhantes na base SNIS: índice de atendimento urbano com coleta de esgotos sanitários referido aos municípios atendidos com água (IN024) e índice de atendimento urbano com coleta de esgotos sanitários referido aos municípios atendidos com esgoto (IN047).

A diferença entre esses indicadores está no denominador. Enquanto o IN024 é composto pela razão entre população urbana atendida com esgotamento sanitário e a população urbana residente do(s) município(s) com abastecimento de água, o IN047 é constituído pela razão entre população urbana atendida com esgotamento sanitário e população urbana residente do(s) município(s) com esgotamento sanitário (SNIS, 2017).

SNIS (2017) define população urbana residente do(s) município(s) com abastecimento de água como sendo o valor da soma da(s) população(ões) urbana(s) residente(s) no(s) município(s) em que o prestador de serviços atua com serviços de abastecimento de água. Já a definição de população urbana residente do(s) munícipio(s) com esgotamento sanitário é o valor da soma da(s) população(ões) urbana(s) residente(s) no(s) município(s) em que o prestador de serviços atua com serviços de esgotamento sanitário.

Nesse contexto, entende-se que o indicador IN047 seria o mais pertinente para retratar o desempenho de um prestador de serviços, uma vez que considera a população que se deve aten- der com esgotamento sanitário, e não de acordo com a população que se deve atender com abastecimento de água, que pode nem ser o escopo de trabalho do prestador de serviços, no caso, por exemplo, de ele atuar em uma cidade com esgotamento sanitário e em outra cidade com abastecimento de água.

Observa-se ainda que o indicador IN056, que retrata o índice de atendimento total com coleta de esgotos sanitários, utiliza como denominador a população total residente do(s) município(s) atendido(s) com abastecimento de água, sendo que essa variável é definida por SNIS (2017) como sendo o valor da soma da(s) população(ões) total(is) residente(s) (urbana(s) e rural(is)) do(s) município(s) (sede(s) municipal(is) e localidade(s)) em que o prestador de serviços atua com serviços de abastecimento de água.

Isto posto, pelo mesmo raciocínio realizado para justificar a preferência pelo indicador IN047 em vez do IN024, considera-se que o indicador IN056 não seria o mais apropriado para representar o atendimento total com coleta de esgotos. Porém, pelo fato de SNIS (2017) não disponibilizar outro indicador que melhor represente o atendimento total com coleta de esgotos, o indicador em questão foi selecionado e utilizado no presente trabalho.

Diante do exposto, os indicadores de desempenho selecionados da base SNIS foram 24. A Fig. 4 apresenta os graus de recorrência para tais indicadores. 


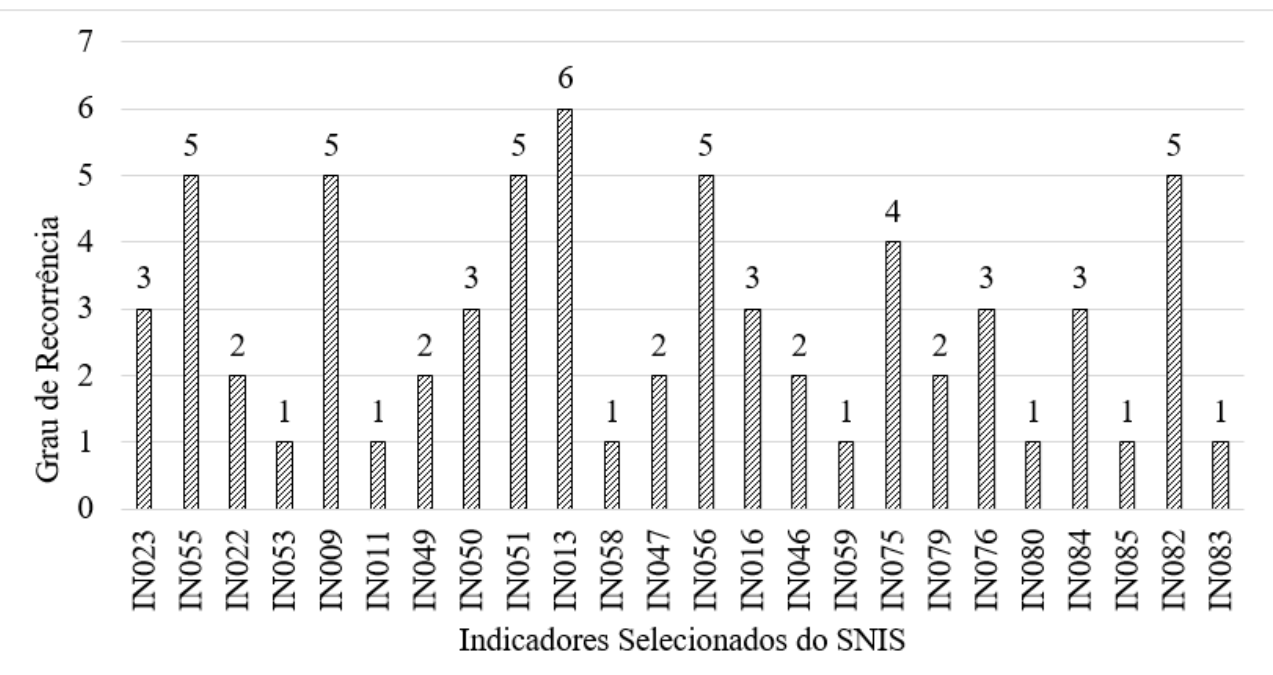

Figura 4 - Indicadores de desempenho selecionados do SNIS e seus graus de recorrência.

De acordo com a Fig. 4, em um primeiro momento percebe-se que o atendimento à população total com rede de água e com coleta de esgotos sanitários é considerada muito mais importante do que somente atender à população urbana com esses serviços. Isso é representado pela considerável maior recorrência dos indicadores IN055 e IN056 em face dos indicadores IN023 e IN047, respectivamente.

Atenta-se ainda para o fato de que a temática perdas de água tem bastante relevância na avaliação de sistemas de abastecimento de água, dado que os indicadores que abordam esse tópico foram recorrentes em quase metade dos sistemas de avaliação estudados; são eles: índice de hidrometração (IN009), índice de perdas por ligação (IN051) e índice de perdas de faturamento (IN013).

Importante ressaltar em relação ao índice de perdas de faturamento que, no caso em que os volumes de água faturados sejam superiores aos produzidos, o indicador assume resultado negativo e incoerente. Tal fato decorre dos critérios de faturamento adotados no Brasil, e que incluem (MIRANDA; KOIDE, 2003):
- Usuários cujas ligações não são micromedidas, sendo faturado um volume fixo mensal, em torno de 10 a $15 \mathrm{~m}^{3}$;

- Usuários cujas ligações são micromedidas e que consomem um volume mensal inferior ao volume mínimo faturável, têm faturado o mesmo volume fixo mensal;

- Usuários cujas ligações não são micromedidas, mas com problemas na hidrometração, o faturamento se dá pelo consumo médio mensal.

Outros indicadores que retratam as perdas de água e que merecem observação são o índice bruto de perdas lineares (IN050) e o índice de perdas por ligação (IN051). Alegre et al. (2006) sugerem a aplicação do IN050 somente para densidade de ramais inferior a 20 un.km-1, enquanto para valores acima de 20 un.km-1, os autores recomendam utilizar apenas o IN051. Observa-se que pelo fato de o SNIS conter informações provenientes de inúmeros e diversos sistemas de abastecimento de água, ambos os indicadores foram considerados para fim de avaliação da relevância, aplicabilidade e objetivo. 
Os indicadores que retratam o consumo de energia elétrica em sistemas de abastecimento de água e esgotamento sanitário, IN058 e IN059, respectivamente, merecem reflexão pela visão dos presentes autores, uma vez que não utilizam o consumo específico normalizado. Esse consumo é considerado pelos sistemas ARCE, ERSAR e IWA, bem como por outros diversos estudos de eficiência energética no setor de saneamento, consumo o qual é calculado pela razão entre o consumo de energia elétrica para bombeamento ( $k W h$ ) e o volume de água/esgotos bombeado a uma altura manométrica padrão de $100 \mathrm{mca}$ $\left(\mathrm{m}^{3} .100 \mathrm{~m}^{-1}\right)$, resultando em $\mathrm{kWh} . \mathrm{m}^{-3} .100 \mathrm{~m}^{-1}$ (MATOS et al., 2003; ALEGRE et al., 2006; ARCE, 2013; ERSAR, 2015).
No que tange à qualidade dos serviços, verificase que dois indicadores se destacaram, sendo um para abastecimento de água e outro para esgotamento sanitário, a saber: incidência das análises de cloro residual fora do padrão (IN075) e extravasamentos de esgotos por extensão de rede (IN082). O IN075 retrata a preocupação das entidades com a qualidade de água fornecida dentro dos padrões legais aos usuários. Já o IN082 simboliza o correto dimensionamento, operação e manutenção dos sistemas de esgotos.

A Tabela 2 apresenta os indicadores operacionais e de qualidade do SNIS que não apresentaram similaridade quanto à formulação e ao objetivo perante pelo menos um indicador dos demais sistemas de avaliação.

Tabela 2 - Indicadores operacionais e de qualidade do SNIS que não apresentaram similaridade perante os indicadores dos sistemas de avaliação estudados.

\begin{tabular}{|c|c|c|c|}
\hline Serviço & Código & Indicador & Unidade \\
\hline \multicolumn{4}{|c|}{ Indicadores Operacionais - Água } \\
\hline Água & IN001 & Densidade de economias de água por ligação & econ.lig ${ }^{-1}$ \\
\hline Água & IN010 & Índice de micromedição relativo ao volume disponibilizado & $\%$ \\
\hline Água & IN014 & Consumo micromedido por economia & $\mathrm{m}^{3} \cdot \mathrm{mês}^{-1} \cdot$ econ $^{-1}$ \\
\hline Água & IN017 & Consumo de água faturado por economia & $\mathrm{m}^{3} \cdot \mathrm{mês}^{-1} \cdot$ econ $^{-1}$ \\
\hline Água & IN020 & Extensão da rede de água por ligação & m.lig $^{-1}$ \\
\hline Água & IN025 & Volume de água disponibilizado por economia & $\mathrm{m}^{3} \cdot \mathrm{mês}^{-1} \cdot \mathrm{econ}^{-1}$ \\
\hline Água & IN028 & Índice de faturamento de água & $\%$ \\
\hline Água & IN043 & Participação das economias residenciais de água no total das economias de água & $\%$ \\
\hline Água & IN044 & Índice de micromedição relativo ao consumo & $\%$ \\
\hline Água & IN052 & Índice de consumo de água & $\%$ \\
\hline Água & IN057 & Índice de fluoretação de água & $\%$ \\
\hline \multicolumn{4}{|c|}{ Indicadores Operacionais - Esgotos } \\
\hline Esgotos & IN015 & Índice de coleta de esgoto & $\%$ \\
\hline Esgotos & IN021 & Extensão da rede de esgoto por ligação & m.lig ${ }^{-1}$ \\
\hline \multicolumn{4}{|c|}{ Indicadores de Qualidade } \\
\hline Água & IN071 & Economias atingidas por paralisações & econ.paralis ${ }^{-1}$ \\
\hline Água & IN072 & Duração média das paralisações & horas.paralis $^{-1}$ \\
\hline Água & IN073 & Economias atingidas por intermitências & econ.interrup $^{-1}$ \\
\hline Água & IN074 & Duração média das intermitências & horas.interrup ${ }^{-1}$ \\
\hline Esgotos & IN077 & Duração média dos reparos de extravasamentos de esgotos & horas.extrav ${ }^{-1}$ \\
\hline
\end{tabular}

Fonte: Adaptado de SNIS (2017).

Por último, pondera-se que a base SNIS e seus respectivos indicadores servem ao contexto e à realidade da maioria dos prestadores de serviços de abastecimento de água e de esgotamento sanitário no Brasil, mas podem não ser suficientes e, consequentemente, ideais, para a avaliação de prestadores de melhor nível de desempenho, aos quais poderiam ser aplicados indicadores mais sofisticados. Nesse contexto, inserem-se, por exemplo, outros indicadores já recomendados 
pela IWA, tais como (MATOS et al., 2003; ALEGRE et al., 2006): reúso de água, grau de tratamento de esgotos, reutilização de lodo, grau de automação e controle, dentre outros.

Selecionados e avaliados os indicadores do SNIS, realizou-se a consulta aos especialistas pelo Método Delphi. A Tabela 3 exibe a quantidade de especialistas participantes, as taxas de abstenção obtidas em cada rodada da pesquisa e uma comparação com as abstenções segundo Wright e Giovinazzo (2000).

Tabela 3 - Quantidade de painelistas e taxas de abstenção nas etapas da pesquisa.

\begin{tabular}{|c|c|c|c|}
\hline \multirow{2}{*}{ Serviço } & \multirow{2}{*}{ Código } & Pesquisa & $\begin{array}{c}\text { Wright e Giovinazzo } \\
\text { (2000) }\end{array}$ \\
\cline { 3 - 4 } & & - & - \\
\hline $\begin{array}{c}\text { Painelistas } \\
\text { convidados }\end{array}$ & 95 & $48 \%$ & 30 a $50 \%$ \\
\hline $1^{\mathrm{a}}$ rodada & 49 & $22 \%$ & 20 a 30\% \\
\hline $2^{\mathrm{a}}$ rodada & 38 & & \\
\hline
\end{tabular}

Constata-se que as taxas de abstenção obtidas nas duas etapas da pesquisa estão dentro das faixas descritas por Wright e Giovinazzo (2000), entretanto a abstenção da $1^{1}$ rodada foi bem alta, próxima do valor superior descrito por esses autores.

Quando se calcula a taxa de abstenção total, ou seja, a razão entre o número de painelistas não participantes da $2^{\mathrm{a}}$ rodada e o número de painelistas convidados, nota-se que o valor é de $60 \%$.
Segundo Gordon (1994), as taxas de abstenção totais variam de 25 a $60 \%$, portanto, apesar de a taxa de abstenção total da pesquisa em questão estar dentro dessa faixa, observa-se que a mesma foi considerável, estando no limite superior.

Perante tais fatos, levantam-se as seguintes hipóteses com relação às altas taxas de abstenção:

- Grande parcela dos especialistas não era conhecida dos autores;

- Não houve contato presencial dos autores com os especialistas, dado que a pesquisa foi desenvolvida por meio de contato eletrônico (correio eletrônico);

- O envio do $1^{\circ}$ questionário foi em julho, mês comum de férias, principalmente no meio acadêmico.

É importante salientar que, apesar de a taxa de abstenção total ser o valor máximo descrito por Gordon (1994), considera-se que o número final de especialistas que participaram da pesquisa foi o suficiente para a obtenção satisfatória dos graus de importância dos indicadores de desempenho estudados.

Apresentam-se a seguir, na Fig. 5, o número e o percentual dos painelistas convidados e dos participantes das duas rodadas por área de atuação do setor de saneamento.

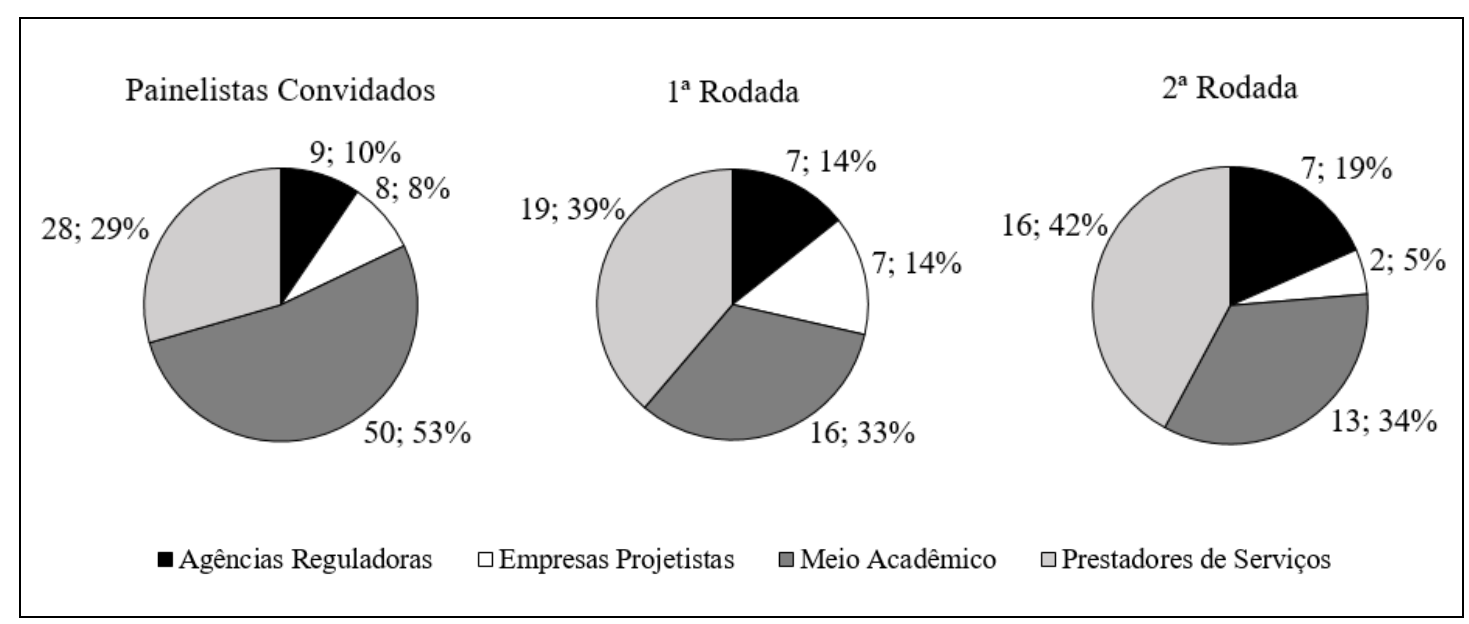

Figura 5: Número e percentual dos painelistas por área de atuação nas etapas da pesquisa. 
Em face da Fig. 5, verifica-se que as empresas projetistas, apesar de exibirem a menor taxa de abstenção na $1^{\mathrm{a}}$ rodada, foram as que apresentaram a maior taxa de abstenção total: valor de $75 \%$.

Outra área que apresentou uma alta taxa de abstenção total, de $74 \%$, foi o meio acadêmico. Tal fato já era esperado, visto que é comum os representantes dessa área tirarem férias no mês de julho ou estarem atarefados com o final de semestre. Isso justifica o porquê de essa área ter um maior número de especialistas convidados em relação às outras áreas.

Os prestadores de serviços obtiveram uma taxa de abstenção total em torno de $43 \%$, valor intermediário na escala descrita por Gordon (1994).
Por fim, destaca-se a baixa taxa de abstenção total das agências reguladoras, cerca de $22 \%$. Infere-se que essa ocorrência se deve ao fato de os profissionais dessa área terem uma maior preocupação e conhecimento da importância acerca de estudos que abordem as temáticas: indicadores de desempenho e avaliação de desempenho de prestadores de serviços de abastecimento de água e esgotamento sanitário.

Realizada a consulta aos especialistas, a partir dos resultados da $2^{\mathrm{a}}$ rodada, calcularam-se as médias aritméticas e os desvios padrão dos graus de importância dos indicadores de desempenho selecionados, conforme apresentado na Tabela 4.

Tabela 4 - Médias e desvios padrão dos graus de importância dos indicadores de desempenho selecionados.

\begin{tabular}{|c|c|c|}
\hline Indicador de Desempenho & Média do Grau de Importância & $\begin{array}{l}\text { Desvio Padrão do Grau de } \\
\text { Importância }\end{array}$ \\
\hline IN023 - Índice de atendimento urbano com rede de água & 4,68 & 0,57 \\
\hline IN055 - Índice de atendimento total com rede de água & 4,39 & 0,86 \\
\hline IN022 - Consumo médio per capita de água & 4,08 & 1,17 \\
\hline IN053 - Consumo médio de água por economia & 3,66 & 1,15 \\
\hline IN009 - Índice de hidrometração & 4,76 & 0,49 \\
\hline IN011 - Índice de macromedição & 4,61 & 0,59 \\
\hline IN049 - Índice de perdas na distribuição & 4,76 & 0,63 \\
\hline IN050 - Índice bruto de perdas lineares & 4,00 & 0,94 \\
\hline IN051 - Índice de perdas por ligação & 4,29 & 0,80 \\
\hline IN013 - Índice de perdas faturamento & 4,21 & 1,02 \\
\hline IN058 - Índice de consumo de energia elétrica em sistemas de abastecimento de água & 4,32 & 0,84 \\
\hline IN047 - Índice de atendimento urbano com coleta de esgotos sanitários & 4,74 & 0,50 \\
\hline IN056 - Índice de atendimento total com coleta de esgotos sanitários & 4,13 & 0,96 \\
\hline IN016 - Índice de tratamento dos esgotos em relação aos esgotos coletados & 4,73 & 0,61 \\
\hline IN046 - Índice de tratamento dos esgotos em relação aos esgotos gerados & 4,57 & 0,77 \\
\hline IN059 - Índice de consumo de energia elétrica em sistemas de esgotamento sanitário & 4,13 & 1,02 \\
\hline IN075 - Incidência das análises de cloro residual fora do padrão & 4,47 & 0,69 \\
\hline IN079 - Índice de conformidade da quantidade de amostras - cloro residual & 4,13 & 1,02 \\
\hline IN076 - Incidência das análises de turbidez fora do padrão & 4,39 & 0,72 \\
\hline IN080 - Índice de conformidade da quantidade de amostras - turbidez & 4,11 & 1,03 \\
\hline IN084 - Incidência das análises de coliformes totais fora do padrão & 4,79 & 0,47 \\
\hline IN085 - Índice de conformidade da quantidade de amostras - coliformes totais & 4,50 & 0,80 \\
\hline IN082 - Extravasamentos de esgotos por extensão de rede & 3,97 & 1,24 \\
\hline IN083 - Duração média dos serviços executados & 3,79 & 1,19 \\
\hline
\end{tabular}


Da observação da Tabela 4, constatam-se os seguintes aspectos interessantes acerca da opinião dos especialistas sobre os indicadores de desempenho selecionados:

- As médias aritméticas para o atendimento urbano com rede de água e com coleta de esgotos foram maiores que as médias aritméticas para o atendimento total; logo, infere-se a priorização pelo atendimento à população urbana;

- O consumo médio per capita de água atingiu uma média aritmética ligeiramente maior que a média aritmética do consumo médio de água por economia. Deduz-se que essa maior relevância se dá pelo fato do consumo per capita ser um indicador mais comum entre os profissionais do setor de saneamento;

- Os índices de hidrometração e macromedição exibiram médias aritméticas bem próximas, tendo o primeiro se destacado um pouco mais, talvez pelo fato de a micromedição envolver as temáticas de arrecadação e faturamento;

- No campo das perdas, o índice de perdas na distribuição teve um maior destaque, seguido do índice de perdas por ligação e, em seguida, índice de perdas faturamento e índice de perdas lineares. Novamente, infere-se que os indicadores de perdas na distribuição, perdas por ligação e perdas de faturamento foram considerados mais importantes porque são mais usuais entre os especialistas do setor de saneamento;

- O índice de consumo de energia elétrica em SAA se revelou ser um pouco mais importante do que o índice de consumo de energia elétrica em SES. Entende-se que esse destaque é devido aos sistemas de água serem mais desenvolvidos que os sistemas de esgotos em nosso país, portanto a temática da eficiência energética é melhor entendida para SAA e, assim, tem maior relevância para avaliar o desempenho desses sistemas;
- O índice de tratamento dos esgotos em relação aos esgotos coletados foi classificado como sendo um pouco mais importante do que o índice de tratamento dos esgotos em relação aos esgotos gerados, provavelmente pelo entendimento de que, já que os esgotos são coletados, devem ser tratados;

- No âmbito da qualidade de água, nota-se que há uma maior preocupação com as análises fora do padrão do que com a conformidade da quantidade de amostras;

- Alguns indicadores de desempenho apresentaram maiores desvios padrão, enquanto outros tiveram valores menores para esse parâmetro, o que reflete tanto o consenso como o não consenso entre os especialistas para a importância de alguns indicadores. Destacaram-se o IN084 e IN082 por apresentarem a menor e maior variação, respectivamente;

- Não houve nenhum indicador que teve a média aritmética abaixo de 3,5. Tal fato fundamenta que todos os indicadores selecionados são importantes para a avaliação do desempenho operacional e de qualidade de prestadores de serviços de abastecimento de água e esgotamento sanitário.

\section{CONCLUSÕES}

Com o desenvolvimento do presente estudo, pôde-se concluir que:

- Indicadores de desempenho são utilizados por diversos sistemas nacionais e internacionais de avaliação, o que demonstra a importância dessa ferramenta na avaliação de sistemas de abastecimento de água e esgotamento sanitário. No entanto, sua utilização deve ser realizada com criticidade, sempre observando, além dos resultados apresentados pelos indicadores, as diversas variáveis que influenciam esses resultados e que muitas das vezes não estão incorporadas aos indicadores; 
- Dentre os 43 indicadores operacionais e de qualidade do SNIS, somente 25 são também considerados pelos demais sistemas de avaliação, logo pode-se dizer que $42 \%$ da quantidade total de indicadores não são relevantes para os demais sistemas de avaliação;

- Dentre os indicadores recorrentes, há necessidade de rever: índice de perdas de faturamento (IN013); índice de atendimento urbano com coleta de esgotos sanitários referido aos municípios atendidos com água (IN024); índice de atendimento total com coleta de esgotos sanitários referido aos municípios atendidos com água (IN056); índice de consumo de energia elétrica em sistemas de abastecimento de água (IN058); e índice de consumo de energia elétrica em sistemas de esgotamento sanitário (IN059);

- A base SNIS e seus respectivos indicadores servem ao contexto e à realidade da maioria dos prestadores de serviços de abastecimento de água e de esgotamento sanitário no Brasil, todavia pode não ser suficiente, e, portanto, ideal, para a avaliação de prestadores de melhor nível de desempenho, aos quais poderiam ser aplicados indicadores mais sofisticados, como os recomendados pela IWA;

- A utilização da Metodologia Delphi na consulta aos especialistas do setor de saneamento foi considerada positiva para o alcance dos resultados esperados. Os 38 participantes foram considerados suficientes para a obtenção de dados confiáveis, uma vez que eles representaram todos os setores ligados ao saneamento. Por meio dessa consulta, constatou-se que todos os indicadores selecionados foram considerados importantes para avaliar o desempenho de sistemas de abastecimento de água e esgotamento sanitário.

$\mathrm{O}$ artigo mostra-se relevante ao se considerar que a Lei $n^{\circ} 11.445 / 2007$ estabelece o instrumento de avaliação de desempenho da pres- tação de serviços de abastecimento de água e esgotamento sanitário em nosso país, sendo os indicadores uma ferramenta extremamente necessária para tal.

Diante do exposto, este estudo contribui para o questionamento sobre a relevância, aplicabilidade e o efetivo objetivo de alguns indicadores que constam na base SNIS, que é o maior e mais importante banco de dados do setor de saneamento brasileiro.

\section{CONTRIBUIÇÃO DOS AUTORES}

Todos os autores contribuíram de forma igualitária.

\section{REFERÊNCIAS}

ABES - ASSOCIAÇÃO BRASILEIRA DE ENGENHARIA SANITÁRIA E AMBIENTAL. Guia PNOQS 2015-2016: regulamento e critérios de avaliação. 4. ed. Rio de Janeiro: ABES, 2016. 227 p.

ABNT - ASSOCIAÇÃO BRASILEIRA DE NORMAS TÉCNICAS. NBR ISO 24510: Atividades relacionadas aos serviços de água potável e de esgoto - Diretrizes para a avaliação e para a melhoria dos serviços prestados aos usuários. Rio de Janeiro, 2012.

ADERASA - ASOCIACIÓN DE ENTES REGULADORES DE AGUA POTABLE Y SANEAMIENTO DE LAS AMÉRICAS. Manual de indicadores de gestión para agua potable y alcantarillado sanitario. Assunção: ADERASA, 2007.34 p.

ALEGRE, H.; BAPTISTA, J. M.; CABRERA JR., E.; CUBILLO, F.; DUARTE, P.; HIRNER, W.; MERKEL, W.; PARENA, R. Performance indicators for water supply services. 2. ed. Londres: IWA Publishing, 2006. $312 \mathrm{p}$.

ARCE - AGÊNCIA REGULADORA DE SERVIÇOS PÚBLICOS DELEGADOS DO ESTADO DO CEARÁ. Resolução nº 167, de 05 de abril de 2013. Diário Oficial do Estado do Ceará, Poder Executivo, Fortaleza, CE, 24 abr. 2013. Seção 3, p. 6-41.

AWWA - AMERICAN WATER WORKS ASSOCIATION. Benchmarking performance indicators for water and wastewater: 2013 survey data and analyses report. Denver: AWWA, 2013.

BOM - BUREAU OF METEOROLOGY. National performance report 2014-15: urban water utilities, part A. Melbourne: Bureau of Meteorology, 2016. 140 p.

BRASIL. Lei n 11.445, de 05 de janeiro de 2007. Diário Oficial da República Federativa do Brasil, Poder Executivo, Brasília, DF, 8 jan. 2007. Seção 1, p. 3-7. 
ERSAR - ENTIDADE REGULADORA DOS SERVIÇOS DE ÁGUA E RESÍDUOS. Relatório anual dos serviços de águas e resíduos em Portugal: volume 1 - caracterização do setor de águas e resíduos. Lisboa: ERSAR, 2015. 177 p.

ESTES, G. M.; KUESPERT, D. Delphi in industrial forecasting. Chemical and Engineering News, v. 54, n. 35, p. 40-47. 1976. https:// doi.org/10.1021/cen-v054n035.p040

GORDON, T. J. The Delphi Method. Futures Research Methodology, v. 2, p. 1-30. 1994.

IBNET - THE INTERNATIONAL BENCHMARKING NETWORK. IBNET Indicators. Disponível em: <https://www.ib-net.org/toolkit/ ibnet-indicators/>. Acesso em: 15 jun. 2016.

MATOS, R.; CARDOSO, A.; ASHLEY, R.; DUARTE, P.; MOLINARI, A.; SCHULZ, A. Performance indicators for wastewater services. Londres: IWA Publishing, 2003. 192 p.

MIRANDA, E. C. de; KOIDE, S. Indicadores de perdas da água: o que, de fato, eles indicam? In: Congresso Brasileiro de Engenharia Sanitária e Ambiental, 22., 2003, Joinville. Anais... Joinville: ABES, 2003.

MIRANDA, E. C. de. Sistema Nacional de Informações sobre Saneamento - SNIS. In: GALVÃO JUNIOR, A. C.; SILVA, A. C. Regulação: indicadores para prestação de serviços de água e esgoto. Fortaleza: Expressão Gráfica e Editora Ltda, 2006. p. 75-90.
MOLINARI, A. Panorama mundial. In: GALVÃO JUNIOR, A. C.; SILVA, A. C. Regulação: indicadores para prestação de serviços de água e esgoto. Fortaleza: Expressão Gráfica e Editora Ltda, 2006. p. 54-74.

OFWAT - OFFICE OF WATER SERVICES. Key indicators: guidance. Londres: OFWAT, 2013. $7 \mathrm{p}$.

SILVA, A. C.; BASíLIO SOBRINHO, G. Regulação dos serviços de água e esgoto. In: GALVÃO JUNIOR, A. C.; SILVA, A. C. Regulação: indicadores para prestação de serviços de água e esgoto. Fortaleza: Expressão Gráfica e Editora Ltda, 2006. p. 145-159.

SNIS - SISTEMA NACIONAL DE INFORMAÇÕES SOBRE SANEAMENTO. Diagnóstico dos Serviços de Água e Esgotos - 2015. Brasília: SNSA/MCIDADES, 2017.212 p.

SNIS - SISTEMA NACIONAL DE INFORMAÇÕES SOBRE SANEAMENTO. Institucional. Disponível em:<http://www.snis.gov.br/ institucional-snis>. Acesso em: 13 abr. 2018.

WRIGHT, J. T. C.; GIOVINAZZO, R. A. Delphi: uma ferramenta de apoio ao planejamento prospectivo. Caderno de Pesquisas em Administração, São Paulo, v. 1, n. 12, p. 54-65, abr./jun. 2000.

XIMENES, M. M. A. F. A ABAR e a construção de instrumentos para a regulação. In: GALVÃO JUNIOR, A. C.; SILVA, A. C. Regulação: indicadores para prestação de serviços de água e esgoto. Fortaleza: Expressão Gráfica e Editora Ltda, 2006. p. 11-28. 